Société d'histoire de la révolution de 1848 et des révolutions du XIXe siècle

$46 \mid 2013$

L'espace du politique en Allemagne au XIX' ${ }^{\mathrm{e}}$ siècle

\title{
Guillaume Cuchet, Les voix d'Outre-tombe. Tables tournantes, spiritisme et société au XIX siècle
}

Collection L'Univers historique, Paris, Le Seuil, 2012, 458 p. ISBN :

978-2-02-102128-8. 25 euros

\section{Nicole Edelman}

\section{OpenEdition}

\section{Journals}

Édition électronique

URL : http://journals.openedition.org/rh19/4485

DOI : $10.4000 /$ rh 19.4485

ISSN : $1777-5329$

\section{Éditeur}

La Société de 1848

\section{Édition imprimée}

Date de publication : 1 juin 2013

Pagination : $211-213$

ISSN : 1265-1354

Référence électronique

Nicole Edelman, « Guillaume Cuchet, Les voix d'Outre-tombe. Tables tournantes, spiritisme et société au xIx $x^{e}$ siècle ", Revue d'histoire du XIXe siècle [En ligne], 46 | 2013, mis en ligne le 13 janvier 2014, consulté le 22 septembre 2020. URL : http://journals.openedition.org/rh19/4485 ; DOI : https://doi.org/ $10.4000 /$ rh19.4485

Ce document a été généré automatiquement le 22 septembre 2020

Tous droits réservés 


\section{Guillaume Cuchet, Les voix d'Outre- tombe. Tables tournantes, spiritisme et société au XIX siècle}

Collection L'Univers historique, Paris, Le Seuil, 2012, 458 p. ISBN :

978-2-02-102128-8. 25 euros

\section{Nicole Edelman}

\section{RÉFÉRENCE}

Guillaume Cuchet, Les voix d'Outre-tombe. Tables tournantes, spiritisme et société au XIX siècle, collection L'Univers historique, Paris, Le Seuil, 2012, 458 p. ISBN :

978-2-02-102128-8. 25 euros

1 Le spiritisme, cette nouvelle religion qui naît en France en 1857, intéresse Guillaume Cuchet en tant que symptôme culturel d'une société où se développe à la fois une industrie puissante avec ses techniques nouvelles, une science qui réinterprète la matière et l'univers et un christianisme qui s'essouffle. « Comment cette petite histoire [...] soulève-t-elle et gonfle-t-elle la grande ?» (p. 19) questionnait déjà Philippe Muray dans son XIXe siècle à travers les âges ${ }^{1}$. Dans Les voix d'Outre-tombe, l'historien tente de répondre à cette interrogation et pour ce faire, il ouvre son étude en mettant en regard les versions nationales de ce nouveau spiritualisme en France de 1848 à 1875 et aux États-Unis à ses tout débuts. Il rappelle ainsi les origines nord-américaines du phénomène avec l'apparition des coups frappés (Spirit Rapping) dans la nouvelle maison de la famille Fox à Hydesville en 1848. Il décrit la diffusion de ce nouveau spiritualisme ancré dans un monde protestant complexe puis son passage en Europe en 1853 analysant le succès des tables tournantes. Ces deux premières parties ne sont pas vraiment novatrices mais Guillaume Cuchet y regroupe les écrits sur ce thème, approfondissant certains points, en clarifiant d'autres sans que soit pourtant toujours bien précisée la différence entre apport personnel et références à des travaux déjà 
publiés. Dans les deux parties suivantes, l'historien étudie la doctrine et le mouvement spirite en les replaçant dans leur contexte culturel, religieux et politique d'émergence puis de diffusion. Il détaille les différents courants qui disputent (faiblement) à Allan Kardec la place de chef de file du mouvement et dresse quelques portraits de spirites dissidents. Dans ce panorama, Guillaume Cuchet néglige à mon avis un ancrage européen qui me paraît pourtant très important et qui fait une des particularités du spiritisme français et européen : la vogue du magnétisme et surtout du somnambulisme magnétique, certes évoquée à plusieurs reprises mais jamais vraiment analysée. Ainsi les figures d'Alphonse Cahagnet et de sa somnambule Adèle Maginot méritaient un plus ample développement que les quelques lignes du livre car ce couple est représentatif de celles et ceux qui interrogèrent les esprits des extra-mondes, et ce depuis la fin du XVIII ${ }^{\mathrm{e}}$ siècle, par le canal du magnétisme. Il réfute aussi l'idée que le spiritisme aurait été un moyen d'émancipation des femmes en France, idée que j'ai moi-même soutenue ${ }^{2}$. Certes, la période étudiée par Guillaume Cuchet est beaucoup trop courte pour que cette hypothèse soit pleinement soutenable. Cependant bien des notions dissonantes par rapport aux normes sociales et culturelles du Second Empire sont exprimées dans les écrits spirites de ces décennies, dans le Livre des esprits comme dans La Revue spirite, concernant par exemple le fotus, le nouveau-né, le mariage, la réincarnation d'un homme en femme, etc. Et si on ne trouve pas en France de conférencières équivalentes à celles qui parcourent les États-Unis - le milieu catholique est, on le sait, réticent à ce type de prise de parole féminine à la différence des protestants -, des femmes médiums vont écrire, publier des romans, tenir des revues, parler devant un public parfois large (notamment à la fin du siècle)... L'analyse de la géographie du spiritisme français permet en revanche à Guillaume Cuchet de montrer de manière convaincante que « la carte du spiritisme paraît bien correspondre dans ses grandes lignes à celle des pays déchristianisés » (p. 253) tout en soulignant des spécificités régionales du rapport anthropologique aux défunts. Le livre de Guillaume Cuchet trouve ensuite toute sa force dans l'étude de ce qu'il appelle le "spiritisme culturel ", titre de la cinquième partie. Il y montre l'ampleur et les caractères d'un retour du religieux sous le Second Empire lié aussi «à la discrétion de la philosophie universitaire» (p. 275). Il analyse les raisons de la réussite du spiritisme dans ce contexte, retrouvant des traces de « spiritisme latent » dans la piété catholique : goût du merveilleux, mise en retrait de la " pastorale de la peur » (p. 285) et essor de la dévotion aux âmes du purgatoire, thème que Guillaume Cuchet avait largement traité dans sa thèse de doctorat ${ }^{3}$. Ici, il soutient l'idée que le spiritisme s'inscrit dans le mouvement plus large d'une "généralisation des formes modernes du "culte des morts", ce culte familial du souvenir et de la tombe qui est un des ancrages anthropologiques et culturels les plus forts et les plus unanimes du XIXe siècle» (p.313), qu'on peut aussi nommer «deuil romantique » ou «deuil victorien ». Il souligne aussi combien le spiritisme qui fait de la pluralité des mondes un des fondements de sa croyance rejoint la popularité de l'astronomie et combien l'astronome Camille Flammarion a contribué à l'essor de la religion spirite qu'il a côtoyée pendant quelques années. La dernière partie de l'ouvrage consacrée à l'antispiritisme est riche de l'apport des nouvelles sources romaines ouvertes au Vatican que l'auteur a dépouillées et qui irriguent - avec bien d'autres - le chapitre consacré à la lutte de l'Église catholique contre le spiritisme dont Guillaume Cuchet analyse à la fois les silences et les combats. Rome n'a pas en effet formellement condamné le spiritisme sous le Second Empire mais seulement mis à l'index certains des ouvrages spirites. Après un chapitre sur "l'antispiritisme laïque », le livre se 
termine au début de la Troisième République, en 1875, puisque Guillaume Cuchet considère que cette année marquée par des procès autour de la photographie des esprits clorait "une époque du spiritisme", celle que l'auteur nomme "sa grande époque » (p. 404), date et affirmation qu'on pourrait discuter puisque la fin de siècle et la Grande Guerre verront un grand renouveau de cette religion. Le livre présente donc une synthèse de nombreux travaux antérieurs sur ce thème du spiritisme naissant tout en apportant des approfondissements et des éléments nouveaux.

\section{NOTES}

1. Philippe Muray, Le XIX ${ }^{\mathrm{e}}$ siècle à travers les âges, Paris, Denoël, 1984.

2. Nicole Edelman, Voyantes, guérisseuses, visionnaires en France, 1785-1914, Paris, Albin Michel, 1995.

3. Guillaume Cuchet, Le crépuscule du purgatoire, Paris, Armand Colin, 2005. 